\title{
Do Project Manager's Utilise Potential Customers in E-Commerce Developments?
}

\author{
Julian Terry and Craig Standing \\ Edith Cowan University, Perth, Australia
}

\section{j.terry@ecu.edu.au c.standing@ecu.edu.au}

\begin{abstract}
In e-commerce, customers have become Information System users. In this environment of nonmandatory usage, remote, untrained users need to quickly feel comfortable and satisfied with a site encounter. Throughout the literature for four decades, a commonly cited factor pertaining to system success has been user participation in the systems development process. Among other things this is likely to lead to increased user satisfaction and the perceived usefulness of the application.

This study surveys project leaders regarding customer participation in e-commerce development activities, as well as several constraints that may hinder this participation. The business need for a rewarding customer experience on an e-commerce site would suggest customer input would substantially influence the site design. The study finds that although participation by customers in developmental activities is occurring, it is having little influence on the design of the site.
\end{abstract}

Keywords: User participation, project management, electronic commerce, systems development

\section{Introduction}

Since the 1960's it has been generally acknowledged that user participation in the Information Systems (IS) development process increases the likelihood of project success (Barki \& Hartwick 1994; Foster \& Franz 1999). Put another way, lack of communication between users and developers has been a common theme in the well-documented reasons for failures in IS implementations (Bussen \& Myers, 1997). User involvement is likely to result in increased user satisfaction (Garceau, Jancura, \& Kneiss, 1993), and the perceived usefulness of the application (Foster \& Franz, 1999; Franz \& Robey, 1986; McKeen, Guimaraes, \& Wetherbe, 1994). Foster and Franz (1999) emphasise the need for user involvement, most importantly in the early stages of development, concluding, "managers should actively seek user involvement in systems development activities" (p.345).

The portfolio of applications being developed today has changed with the emergence of the ECommerce (EC) business paradigm. Organisations are capitalising on the potential of new technologies such as the Internet, Intranets

Material published as part of this journal, either on-line or in print, is copyrighted by Informing Science. Permission to make digital or paper copy of part or all of these works for personal or classroom use is granted without fee provided that the copies are not made or distributed for profit or commercial advantage AND that copies 1) bear this notice in full and 2) give the full citation on the first page. It is permissible to abstract these works so long as credit is given. To copy in all other cases or to republish or to post on a server or to redistribute to lists requires specific permission from the publisher at Publisher@InformingScience.org and the World Wide Web to improve communications and transaction efficiency, reduce operation costs and increase market share. This paradigm shift in business has been supported by applications with a different focus. While organizations continue to implement IS for internal use and to in- 
tegrate with known business partners, the focus of this paper is business-to-customer (B2C) applications that are available for universal use.

The literature to date regarding user participation in IS development has not differentiated between applications designed for traditional environments or for B2C. In comparing the two domains, Fraternali (1999) states:

"Applications for the Internet in such domains as electronic commerce, digital libraries and distance learning are characterized by an unprecedented mix of features that makes them radically different from previous applications of information technology” (p. 227).

However the underlying process for developing applications is addressed by Yourdon (2000), who questions whether e-business/Internet projects are really that different by suggesting "Ebusiness projects face the same demands pressures and risks as any other kind of IT development project, but to a greater degree". This added pressure comes from not only squeezed timeframes for delivery, but also from the necessity to change accompanying business processes. He suggests also that "the e-business phenomenon is much more fundamental because it creates a much more intimate connection with customers, vendors and suppliers".

One feature of B2C systems that differentiates them from traditional MIS applications is the identity of the "user". Traditional systems are developed for a clearly defined set of known users either in-house or business partners. The development may be undertaken in-house or by external parties, but either way, the user community is clearly identifiable. They are often championing the project and possibly funding it from their budget. Likewise off-the-shelf packages allow organisations to see what they are getting before software purchase. Customisation of the package to meet the organisations needs can then precede implementation. Again the known, distinguishable in-house user community is able to be involved in decisions regarding the adoption and adaptation of the product.

In the global business environment of today, a B2C application is inviting the consideration of the world at large. Rather than serving a known user group, B2C sites may target the world at large. Potential users are diverse in all respects, ethnically, culturally as well as geographically. They are also diverse in their computing skills as noted by Fraternali (1999),

"Universal access by individuals with limited or no skills in the use of computer applications introduces the need of new man-machine interfaces capable of capturing the customer's attention and facilitating access to information" (p.227).

The ability to have representative end-user participation in B2C IS development is radically different from obtaining user involvement in traditional systems. The question is "are potential B2C end-users being included in the development process?" Terry and Standing (2001) in a series of preliminary interviews with five project leaders reported that "despite the business need for remote, untrained users to quickly feel comfortable and satisfied in an e-commerce site encounter, it appears that organisations are making very little effort to engage users in any e-commerce site developmental activities" (p. 671).

This paper investigates the extent of user participation in B2C IS developments by surveying project leaders of substantial B2C developments. Thirty leaders of recently completed projects, were questioned on the role of users throughout the development lifecycle, along with the contingency factors of resource constraints and system impact that may affect the commitment of the organisation to the success of the system. The results are presented. 


\section{Users and User Involvement}

The term "user" is open to ambiguity. Land and Hirschheim (1983) acknowledge the existence of different types of user: senior management who bear ultimate responsibility for the organisation's well-being and who may use outputs of IS developments; middle management who are responsible for the operational staff using the IS, and finally those staff who regularly interact with the system. From project conception, through the development lifecycle each of these users may contribute or participate in IS development activities. The term "user" is not generally defined specifically in the many studies published in literature, beyond the Ives and Olson (1984) definition of them as "representatives of the target user group" (p. 587).

User involvement has traditionally been referred to as participation in the system development process measured as a set of activities that users or their representatives have performed (Baroudi, Olson, \& Ives., 1986; Doll \& Torkzadeh, 1989; Ives \& Olsen, 1984). Barki and Hartwick (1994) proposed a clearer definition for user involvement, distinguishing it from user participation as in other disciplines. They define user participation as a "the assignments, activities and behaviours that users or their representatives perform during the systems development process" (p. 60). User involvement refers to the "subjective psychological state reflecting the importance and personal relevance that a user attaches to a given system" (p. 60). These definitions appear to have been generally accepted in the ensuing literature (Hunton \& Beeler, 1997; McKeen \& Guimaraes, 1997) as they are in this paper.

The literature has not found the identity of the users or their representatives to be a contentious point. Often all of the three user types above are domiciled in the same workplace and are identifiable to IS development project managers. Their participation in for example, problem definition, specification of requirements, design and testing could be mandated within the organisation. So the users involved in IS projects are clearly identifiable to practitioners and to researchers.

Identifying the user community in $\mathrm{B} 2 \mathrm{C}$ systems development is more difficult. The three user types identified by Land and Hirschheim (1983) still exist. Senior management involvement in the conceptualisation of a system is particularly important given the structural business change that will need to accompany the introduction of EC. While middle management is not as prevalent in the workforce, this group covers expert users who will have essential input developing requirements and design. Organisations will also have operational staff interacting with the system. However another user type has emerged. B2C transactions involve remote customers who may not be known to the organisation. They are the ultimate end-users, but are beyond the accepted definition of users above. They are not staff and do not fall under the control structures of the organisation. Business success is based on their acceptance and usage of the system. However their participation cannot be mandated. Likewise their involvement or attitudinal disposition to the system. We will call this group of users "customer-users".

\section{System Success}

While there is no direct measure for the success of an Information System, (see DeLone \& McLean, 1992), empirical researchers have commonly used user satisfaction as the dependent variable (Doll \& Torkzadeh, 1989; Franz \& Robey, 1986; McKeen \& Guimaraes, 1997; Powers \& Dickson, 1973). Prominent among the independent variables studied for their influence on this measure, are user involvement or participation in the system development process.

Although the efficacy of user involvement in information systems development leading to system success has been the subject of much research, it has not been studied in the context of B2C systems development. However, the concept of system success as measured by user satisfaction may 
be more relevant to B2C developments than to traditional systems. Ensuring a system is successful from a user perspective is related to the following:

\section{Meeting requirements}

For a system to be useful to users it should provide appropriate functionality. This may include providing relevant information, entertainment, downloads, or transaction capabilities.

\section{Usability}

There are many aspects of information systems design that impact on usability including: the design of the user interface, ease of navigation, online and offline help, system performance and error handling (Fisher 1999). With no compulsion to visit and interact with a site, an Internet user needs to feel comfortable with a site's usability - and quickly. If not they can and do take their trade to another site. Shopping cart abandonment rates of 20 to 60 percent per transaction reported by Schwarz (2001) are testament to dissatisfied customers.

It has been said that there is only one chance to make a first impression. In the Internet world it may be better to have no site than an unintuitive one that is unlikely to be revisited. Furthermore customer-users are not availed of the training in application use that traditional system users expect. User support is also not likely to be as readily available. So there is a need for EC developers to be particularly sensitive to usability issues.

\section{Research Methodology}

The relationship between customer-user participation in EC system development and system success, as perceived by the project leader, is the central focus of this paper. This relationship has been ignored in the academic literature to date; it is beyond the scope of the generally accepted definition of "user participation". This paper forms part of a wider study seeking a view of this relationship from several perspectives - the project leader, the business sponsor, internal system users and external customer-users. In this paper we present the initial results of the first 30 responses received from project leaders of recently completed EC developments or substantial redevelopments. The other perspectives relating to the same EC system are being simultaneously captured but not yet analysed. The business sponsor is surveyed regarding costs and strategic, transactional, informational and general benefits. Internal users are asked about their participation in the EC development - they are the current equivalent of the user of traditional MIS developments. Their participation will be compared to that of customer-users. Finally, customer-users are asked to evaluate the EC site in terms of usability, information quality, sense of relationship with the organisation, as well as various general questions.

Eighty Australian organisations with recently completed EC sites were randomly selected and personally approached to participate in the study. To date thirty project leaders have responded. They have been responsible for the development of the EC application and are able to respond to questions regarding customer-user participation in the developmental process. There twelve multi-dimensional questions pertaining to potential areas for inclusion of customer-user input throughout the development process:

- requirements gathering

- design

- usability testing

- beta testing

- post-implementation review 
They were also asked for their opinions on several factors that could have constrained the development process. These were:

- time

- financial resources

- access to potential customers

It was hypothesised that customer-user participation in an EC development may be reduced if there was undue time or financial pressure, or access to these customer-users was restricted in some way.

\section{Results}

The section describes an initial reporting and interpretation of the survey data as a precursor to a detailed quantitative analysis.

\section{Customer Profiling}

Sixty percent of respondents developed profiles of people they would target as customers of the EC site. However only $50 \%$ of respondents identified actual targeted customers to provide input to the EC site development process. It appears that profiling and targeting customers that match the profile is not as high a priority for organisations involved in these developments, as having some participation by "potential” users.

\section{Requirements Gathering}

Nearly $85 \%$ of respondents incorporated some form of user participation in the Requirements gathering process. Many used more than one technique. Of these $85 \%$, the technique most used to elicit requirements was the evaluation of comparable sites (64\%). Other techniques that were favoured by project leaders to involve potential users were:

- electronic (email or web-based) surveys (52\%),

- bringing people together for focus groups (40\%),

- conducting telephone surveys (40\%),

- traditional paper-based surveys $(24 \%)$ and

- interviews $(20 \%)$.

It appears that project leaders employ a wide variety of techniques to capture information regarding "what" potential customers would like the site to provide. Fifty two percent of the organisations that embraced user participation utilised 3 to 6 different techniques in the requirements gathering process.

Participation in a process and influence brought to bear on a final product may be quite different. From the above results it appears that the respondent project leaders were keen to utilise potential users. However project leaders were also asked the question, "to what extent did the input from targeted customers influence the content of the site?" Forty four percent of the organisations that embraced user participation indicated that the influence of the targeted customers on the site was zero. Therefore almost half the project leaders that involved customers in determining requirements for their site, were unable to utilise any customer input into the site requirements. Only two project leaders (7\%) indicated that the user participation led to extensive influence on the content of the site. (See Figure 1.) 


\section{Design}

There was a significant fall away of customer participation from requirements gathering to design activities. Fifty percent of all organisations, (or only $60 \%$ of organisations that used customers for requirements gathering), utilised customers for design activities. Of this group the activities and participation rates were as follows:

- a walkthrough of the completed design $(50 \%)$

- developing the structure of the site $(20 \%)$, and

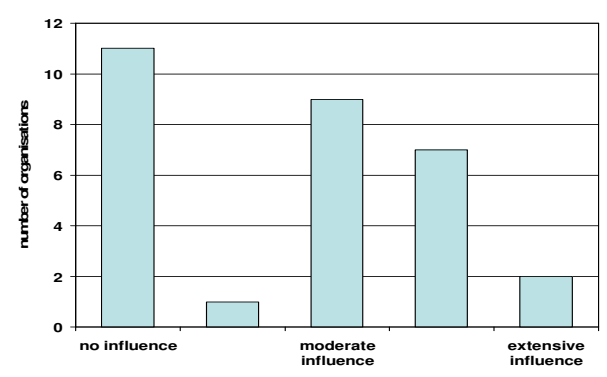

Figure 1: Customer influence on web site requirements

- developing the navigation for the site $(20 \%)$.

Therefore the major design activity in which the project leaders invited customer resources for input, was to provide feedback after the design had been completed. This exceeded customer involvement in developing the design.

\section{Usability Testing}

Fifty three percent of project managers had potential customers perform some form of usability testing on the site. Those organisations that performed usability testing employed a variety of testing techniques as are shown below:

- The customers were observed while performing usability testing (50\%),

- The customers were given specific tasks to perform (31\%),

- The customers' actions were automatically logged as they performed tests (31\%),

- The customers were asked to complete a questionnaire regarding their experiences (25\%),

- The customers were asked to verbalise their thoughts as they performed tests (25\%),

- The customers were recorded while performing usability testing, for later analysis $(0.06 \%)$.

- The setting where the customers performed the tests were:

- In their usual environment (i.e. at home or in their usual workplace) (63\%),

- In a location specified by the developers $(25 \%)$.

\section{Beta Testing}

Forty three percent of organisations released the application to a limited set of customers for beta testing before putting the application into full production. All but one of these organisations had involved customers in usability testing.

\section{Post-implementation Review}

There was very little active seeking of site review feedback from customers. Only 23\% of all organisations asked customers to complete either an

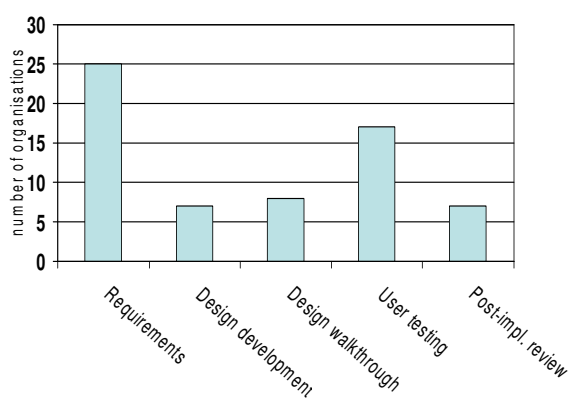

Figure 2: User participation in web site development activities. 
online or paper-based survey. None used a commercially or generally available instrument for this purpose. (See Figure 2.)

The majority of organisations (77\%) provided a passive mechanism for some form of customer feedback - this was a simply providing a link for customers to contact the webmaster concerning problems or suggestions. Sixty percent of organisations indicated that they perform their own review of customer/site interaction by evaluating site logs.

\section{Success}

Project leaders were asked if they considered that the implementation of the EC site had satisfied its business case i.e. that the costs and benefits of its development and implementation were aligned with prior expectations. Sixty three percent of project leader responded positively to this, while $30 \%$ were neutral and $7 \%$ considered the business case had not been met. (See Figure 3.)

\section{Constraints on the EC Devel- opment Project}

\section{Time}

It was hypothesised that development time would be limited, and the pressure of deadlines may limit the time needed to have users participate in the development process. The results do not conclusively support this. Surprisingly $43 \%$ of organisations were revealed they did not have time constraints, while 36\% did. (See Figure 4.)

\section{Financial resources}

Forty percent of project leaders felt they were working under some level of financial constraint. Again, surprisingly $60 \%$ indicated that their projects were not financially constrained or they were neutral regarding the question. (See Figure 5.)

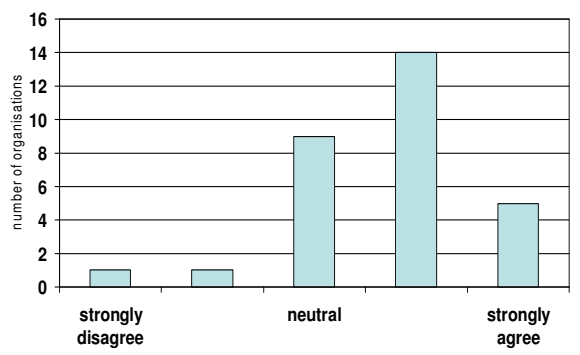

Figure 3: Do project leaders consider the site has satisfied its business case?

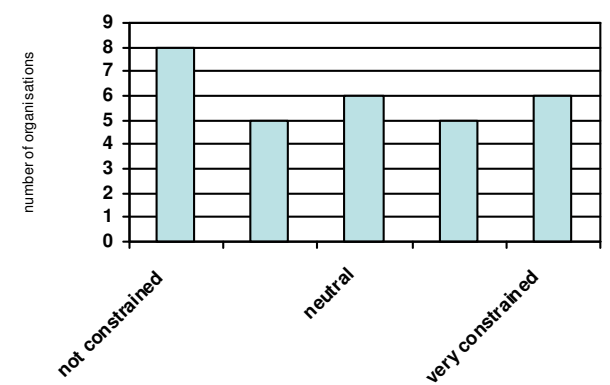

Figure 4: Time as a constraint on the EC development.

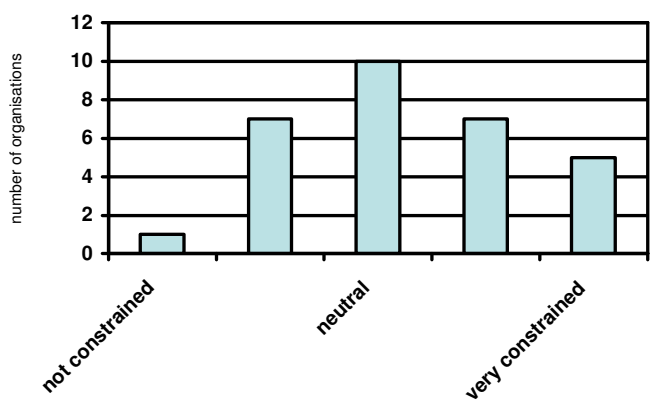

Figure 5: Financial resources as a constraint on the EC development 


\section{Access to potential customers}

Access to potential customers was clearly not a constraint on project leaders in their decision on whether or not to involve customerusers in the project. Sixty percent indicated that access to potential customers did not constrain them. Only $0.06 \%$ felt access to potential customers was constrained in some way. (See Figure 6.)

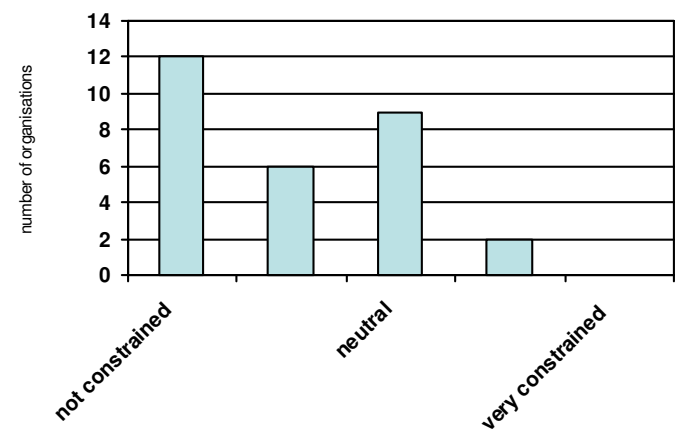

\section{Figure 6: Access to potential customers as a constraint on the EC development}

\section{Discussion}

This paper describes the perspective of project leaders of EC developments, regarding customer participation in projects. The majority of projects (almost $85 \%$ ) have embraced some form of customer participation in the development process. The scale of this participation has varied markedly between development phases. All projects that utilised user participation did so in the requirements elicitation phase, and then to a lesser extent in design and user testing. In fact of the 25 projects that used customers in requirements generation, only 7 continued to use them in developing the design (as opposed to a customer walkthrough of the design, which a further 8 projects utilised). Seventeen organisations involved customers in user testing activities, including both usability and beta testing.

While it is unclear why there is a drop away in user participation after the requirements gathering exercise, the influence these customers exerted on the final site requirements emerges as an interesting statistic. Of the 25 projects that used customers for requirements gathering, 11 (44\%) indicated that the customer input had no influence on the site. Of these 11 organisations, 10 did not utilise customers at all in design activities. It would appear that these project leaders found customers did not add significantly to the requirements of the system. Either the customers espoused what was already known by the organisation about the site requirements, or their input was discarded as being outside the project scope. It is realistic to conclude that many organisations attempting to transact with customers over the web do have a clear idea of what their site is going to provide. In many cases content and functionality for a limited product set is restricted. Navigation is likewise. As the web becomes more accepted as a means of completing commercial transactions, EC site developers and consumers alike have more shared expectations about site usability. The most-performed requirements gathering function by customers, was the evaluation of comparable sites.

Most project leaders (63\%) were positive in their view that the development of the site had met its business case for costs and benefits. However, no clear pattern has emerged from the data regarding the impact of user participation on system success. It appears that user participation does not strongly impact on the success of the system. At best there may be a marginal positive effect overall, but some projects met their business case without user participation at all. Project leaders, however, may not be in the most appropriate position to judge whether or not a development they are responsible for has been successful in a business sense, and this paper is part of a multi- 
perspective study. The project sponsor evaluation of the business case will make an interesting comparison with the project leader view. Likewise, the utility of the site from the customer perspective.

Three contingency factors were selected for this study in an effort to ascertain their affect on customer-user participation. It was hypothesised that if these factors were constrained then so may be the likelihood of customer-user participation. It appeared that all three, time, financial resources, and access to potential customers were not unduly constrained and the customer-user participation or lack of it did not appear to be contingent on these factors. The only contingent factor that was clearly skewed was access to potential customers being particularly unconstrained. Given this, the question raised is why was there not more utilisation of potential customers?

\section{Conclusion}

This research has been motivated by the need for a comprehensive study addressing the relationship between system success and user participation in modern systems development. This paper represents an initial analysis of the first part of that study - the project leader perspective of customer participation throughout development and system success.

The generally accepted traditional view that some user participation is going to impact user satisfaction is not seen to be particularly relevant to EC developers. End-user input to requirements is either not augmenting what the organisation already knows about the site content and functionality, or is being discarded, while in many cases design and acceptance testing have been moved outside the development lifecycle. In other words it takes the form of customer feedback after the system has been implemented.

Myers et al (1996) state that "users expect highly efficient and easy-to-learn interfaces and developers now realize the crucial role the interface plays" (p. 794).

\section{References}

Barki, H. \& Hartwick, J. (1994). Rethinking the concept of user involvement, and user attitude. MIS Quarterly, $18(1), 59-79$.

Baroudi, J. J., Olson, M. H. \& Ives, B. (1986). An empirical study of the impact of user involvement on system usage and information satisfaction. Communications of the ACM, 29 (3), 232-238.

Bussen, W.S., \& Myers, M.D. (1997). Executive information systems failure: A New Zealand case study. PACIS '97, Brisbane, Information systems Management Research Concentration, Queensland University of Technology, Australia.

DeLone, W. H. \& McLean, E. R. (1992). Information systems success: The quest for the dependent variable. Information Systems Research, 3 (1), 60-95.

Doll, W. J. \& Torkzadeh, G. (1989). A discrepancy model of end-user computing involvement. Management Science, 35 (10), 1151-1171.

Foster, S.T. (Jr.) \& Franz, C.R. (1999). User involvement during information systems development: A comparison of analyst and user perceptions of system acceptance. Journal of Engineering and Technology Management, 16, 329-348.

Franz, C.R. \& Robey, D. (1986). Organisational context, user involvement, and the usefulness of information systems. Decision Sciences, 17 (3), 329-356.

Fraternali, P. (1999). Tools and approaches for developing data-intensive web applications: A survey, ACM Computing Surveys, 31 (3), 227-263. 
Garceau, L., Jancura, E. \& Kneiss, J. (1993). Object oriented analysis and design: A new approach to systems development. Journal of Systems Management, 44, 25-33.

Hunton, J.E. \& Beeler, J.D. (1997). Effects of user participation in systems development: A longitudinal experiment. MIS Quarterly, December, 359-383.

Ives, B. \& Olsen, M.H. (1984). User involvement and MIS research: A review of research. Management Science, 30 (5), 586-603.

Land, F. \& Hirschheim, R. (1983). Participative systems design: Rationale, tools and techniques. Journal of Applied Systems Analysis, 10, 91-107.

McKeen, J. D. \& Guimarares, T. (1997). Successful strategies for user participation in systems development. Journal of Management Information systems, 14 (2), 133-150.

McKeen, J.D., Guimaraes, T. \& Wetherbe, J.C. (1994). The relationship between user participation and user satisfaction: An investigation of four contingency factors. MIS Quarterly, December, 427-451.

Myers, B., Hollan, J., Cruz, I. et al. (1996). Strategic directions in human-computer interaction. ACM Computing Surveys, 28 (4), 794-809.

Powers, R. F. \& Dickson, G.W. (1973). MIS project management: Myths, opinions and reality. California Management Review, 15 (3), 147-156.

Schwarz, M. (2001). The care and keeping of online customers. Information Age, Feb-Mar, 61-62.

Terry, J. E. \& Standing C. (2001). User involvement in E-Commerce systems development. Proceedings of the Twelfth Australasian Conference on Information Systems, Coffs Harbour, 671-678.

Yourdon, E. (2000, August 21). Success in e-projects. Computerworld.

\section{Biographies}

Julian Terry is a lecturer is Computer Science at Edith Cowan University in Australia. He is currently completing his $\mathrm{PhD}$ on software development methodologies for e-commerce systems. He teaches in Software Engineering and has published in the Australian Computer Journal and the International Journal of e-Business Management.

Dr Craig Standing is Professor of Strategic Information Management at Edith Cowan University. He received his PhD from the University of Western Australia in 1997. His research specializes in electronic markets, e-commerce adoption and assimilation. He has published widely in Information Systems journals including Journal of Electronic Markets, IS Frontiers and the Journal of Information and Software Technology. 